\title{
Movimento Circular na Auricula
}

\author{
Trabalho lido na Sociedade Arnaldo Vieira de \\ Carvalho pelo Dr. Jairo Ramos.
}

O unico objectivo de nossa palestra, é tornar conhecida e vulgarisada certas noções de cardiologia hoje perfeitamente estabelecidas. A nossa palestra está baseada, ou melhor, nada mais é que interpretação do livro de Th. Lewis "The mechanism and the graphic registration of the heart beat" Se assim procedemos é com o objectivo de vulgarisar o mechanismo de acção da "Auricular Flutter" e da Fibrilação Auricular bem como o seu tratamento. Antes de entrarmos propriamente no assumpto faremos algumas considerações geraes, collocando a assistencia, em sua maioria constituida de estudantes, no mesmo estado de conhecimento em que nos achavamos antes de ler o livro de Th. Lewis já referido.

O tubo cardiaco primitivo é, como o seu nome indica, constituido por um simples tubo com duas extremidades, uma anterior donde parte o systema arterial, outra posterior onde vem ter o systema venoso. Esse tubo é normalmente percorrido por uma onde penistaltica iniciandose no ponto onde vêm ter as veias (seio venoso), e dirigindo-se para o ponto de onde emergem as arterias. Com o evoluir, esse tubo de cylindrico que era, torna-se ampolar. A onda peristalica continua ainda a percorrel-o mo mesmo sentido. Em um estado mais ulterior teremos quatro cavidades, sendo que a mais superioi constitue o seio venoso, as outras tres em um estado mais evoluido darão as quatro cavidades cardiacas. Nos vertebrados inferiores ainda notamos nitida differenciação do seio venoso da auricula. Ainda aqui, segundo experiencias de Gaskell, a contracção nasce no seio venoso, parte mais excitavel do tubo cardiaco primitivo. Se, no coração de um batrachio, fizermos, como Stannius ,uma ligadura separando o seio venoso do resto da auricula, veremos o seio continuar a bater com o rythmo que lhe é proprio, emquanto as outras parte, após um pequeno intervallo, recomeçarão a bater ,independentemente das excitações do seio, com um rythmo proprio e mais lento. (Pois 
o seio venoso regula o rythmo pela maior frequencia de excitações). No coração dos mammiferos não ha essa nitida differenciação do seio venoso e da auricula. Pesquizas ulteriores vieram mostrar na auricula a existen-
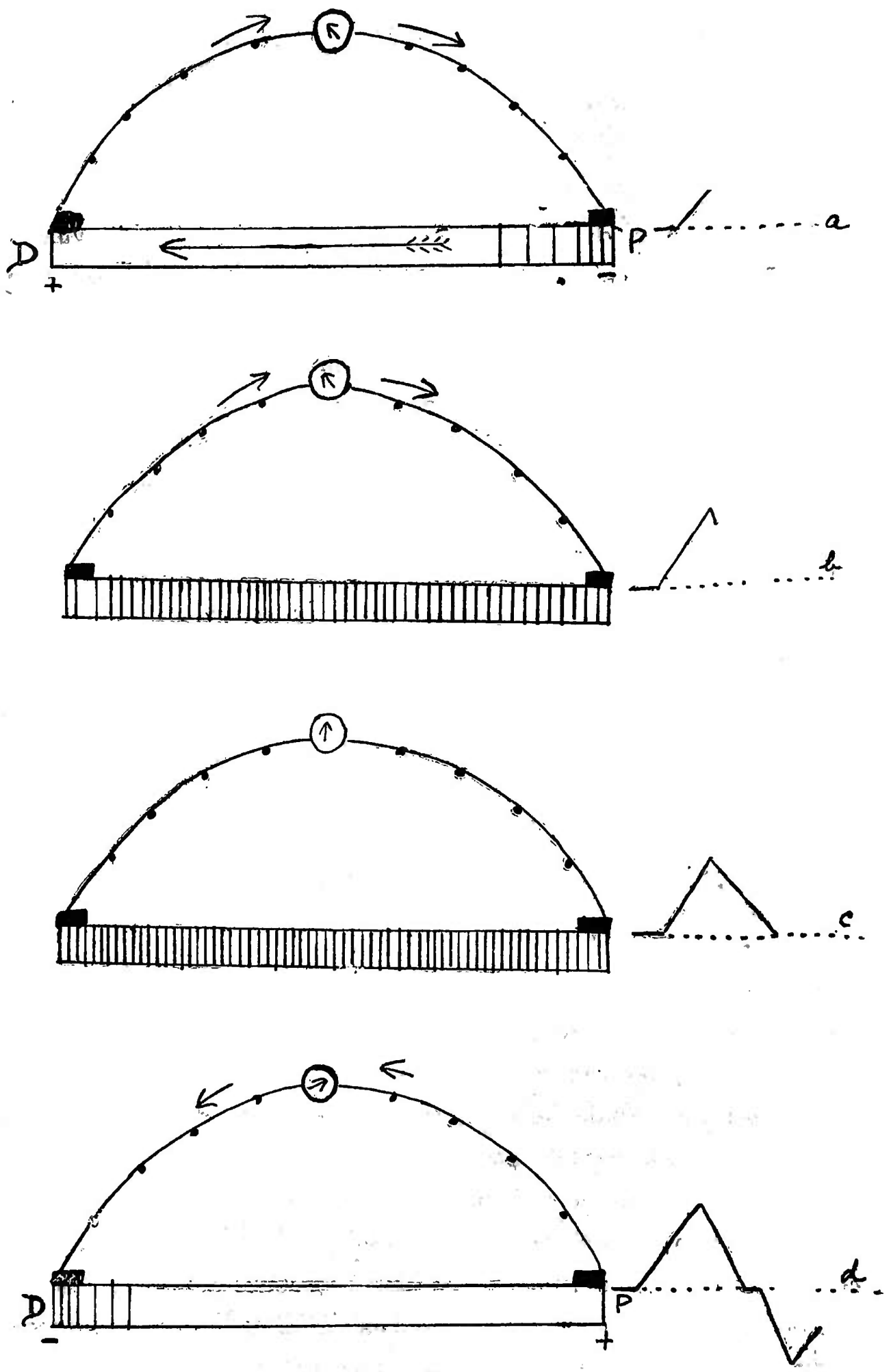

N. 1 
cra de fibras musculares differenciadas, e Keith e Flack, em estudos mais detalhados, descreveran quatro nucleos, (veia cava superior, sinus coronarios, septo auricular e abertura d'as veias pulmonares)'. Dentre esses nucleos, um, pelo seu tamanho e sua riqueza em elementos nervosos, o nucleo sinus auricular, nas visinhanças dia veia cava superior, começou a chamar a attenção dos experimentadores. E' o chamado nodulo sinus auricular ou nodulo de Keith e Flack. Desde então nasceu o noção de um "pace-ma-"

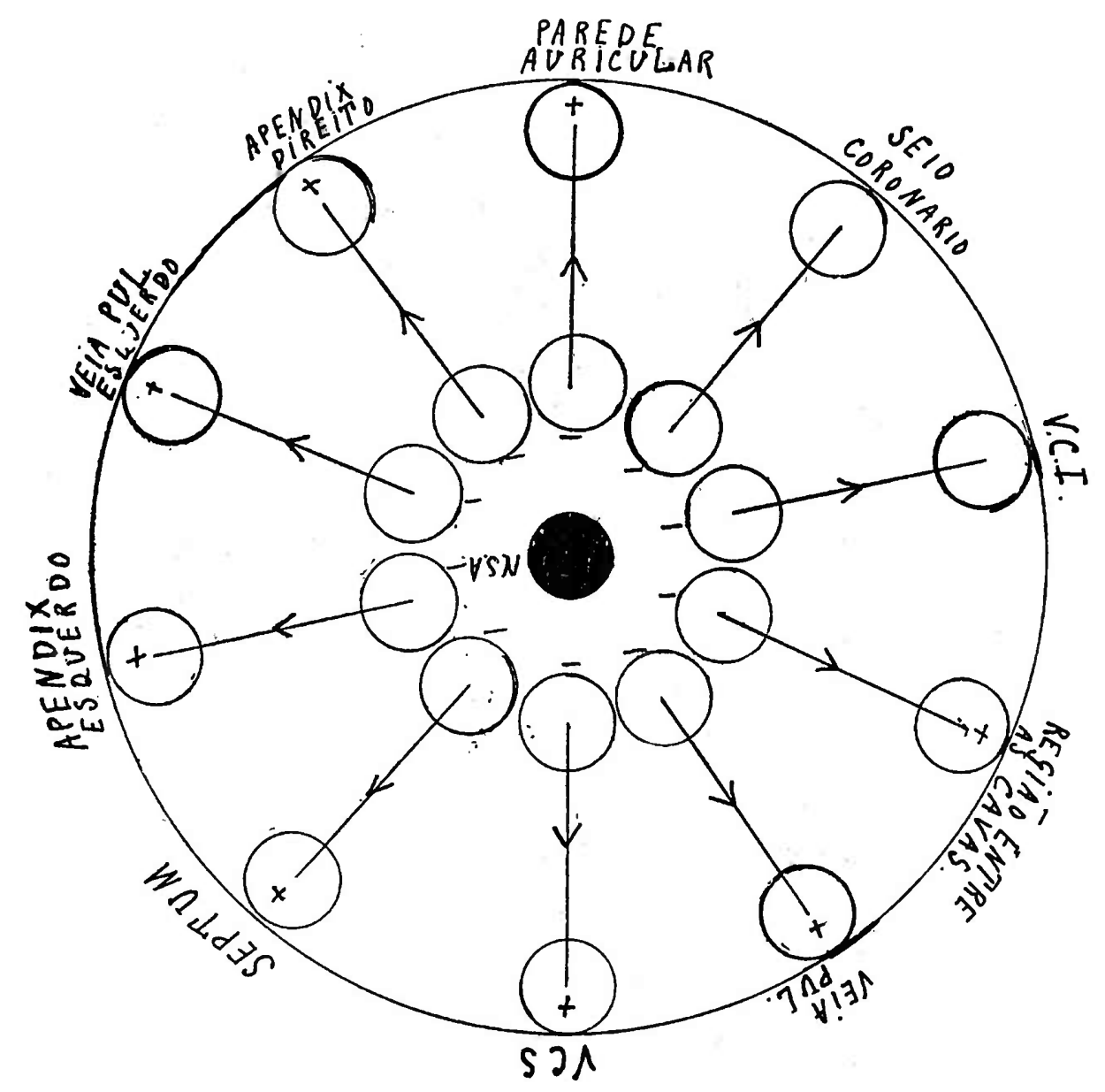

N. 2

ker", isto é, de um ponto regulạdor do rythmo cardiaco nos mammiferos. Antes d'a descoberta de Keith e Flack suppunha-se estar o "pace-maker" localisado nos sulcus terminalis, que seria, nos mammiferos, o limite entre o seio venoso e a auricula. Descripto o nodula sinus auricular, as vistas 'dos esperimentadores para ahi se voltaram e experiencias começaram a ser feitas para a identificação do "pace-mker" ou melhor, do ponto de origem das excitaçães. Muitos foram os methodos empregados, como por 
exemplo excitantes physicos e chimicos, todos esses mecessitando do recurso da circulação artificial que até certo ponto perturbava as conclusões, quando surgiu um novo methodo baseado em uma propriedade de toda fibra muscular. Normalmente, um musculo em repouso está em equilibrio electrico,

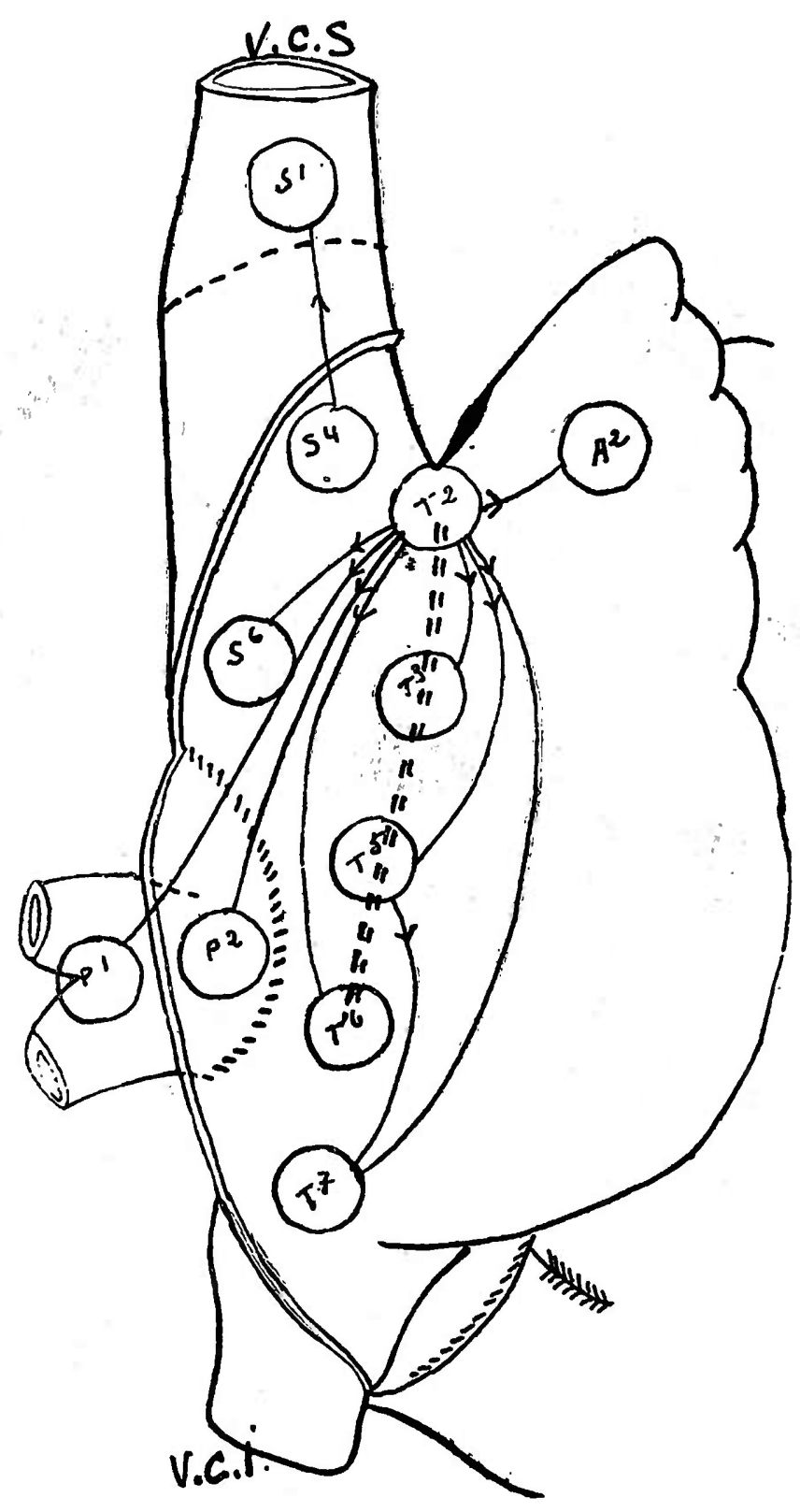

N. 3

isto é, todas as suas partes são isoelectricas. Se excitarmos uma de suas extremidades, o ponto primitivamente excitado ao entrar em contracção, se tornará temporariamente negativo em relação a outra extremidade e uma corrente electrica se desenvolverá correndo do polo positivo, extremi- 
dade não excitada ,para o polo negativo, extremidade excitada. Se ligarmos a um galvanometro, por electrodos não polarisaveis, as duas extremidades do musculo em experiencia, teremos duas deflexões que registradas formarão uma curva diphasica. A primeira deflexão é originaria da excitação de uma extremidade e a segunda indica a chegada dessa onda de excitação a outra extremidade que se tcrnou temporariamente negativa em

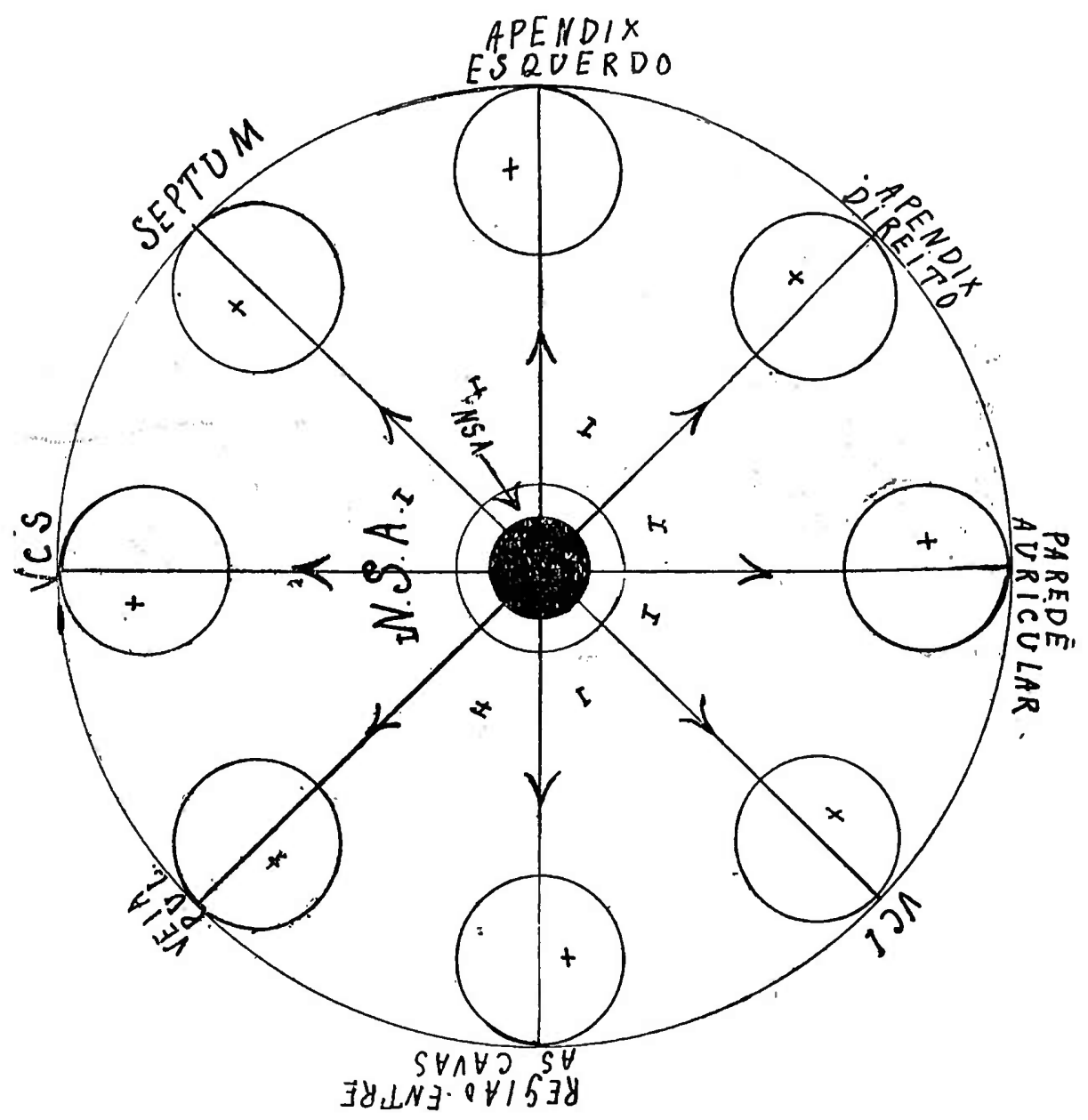

N. 4

relação a primeira. Portanto, todas as vezes que excitamos um musculo, a parte excitada torna-se temporariamente negativa em relação a parte inactiva. A mudança electrica motivada pela excitação induz a formação de uma corrente electrica que correrá do ponto inactivo $(+)$ para o activo (-) e o galvanometro registrará essa corrente com uma deflexão, como veremos no eschema n.' 1. $\left(^{*}\right)$. Uma vez a onda chegada ao ponto distal, esse se tornará negativo em relação ao proximal, e uma nova cơrrente se formará, correndo como a primeira, do polo positivo para o negativo, e o galvanometro registrará essa corrente com um deflexão em sentido in- 
verso da primeira. Se, ao contrario, a parte prime ramente excitada fôr a distal, teremos duas reflexões porem em sentido inverso das anteriores. Aos electrodos não polarisaveis usados, denominamos $Z$ aquelle que primeiro se tornar negativo e ao outro $C$. Todas as vezes que uma curva nos apresentar uma deflexão para cima indica que o ponto que se tornou pr.meiro negativo foi o correspondente ao contacto $Z$. Se isso é observado no musculo commum, nenhuma razão ha para que se não observe nıo coração. Para o coração poderemos usar derivações directas e indirectas. As pri-

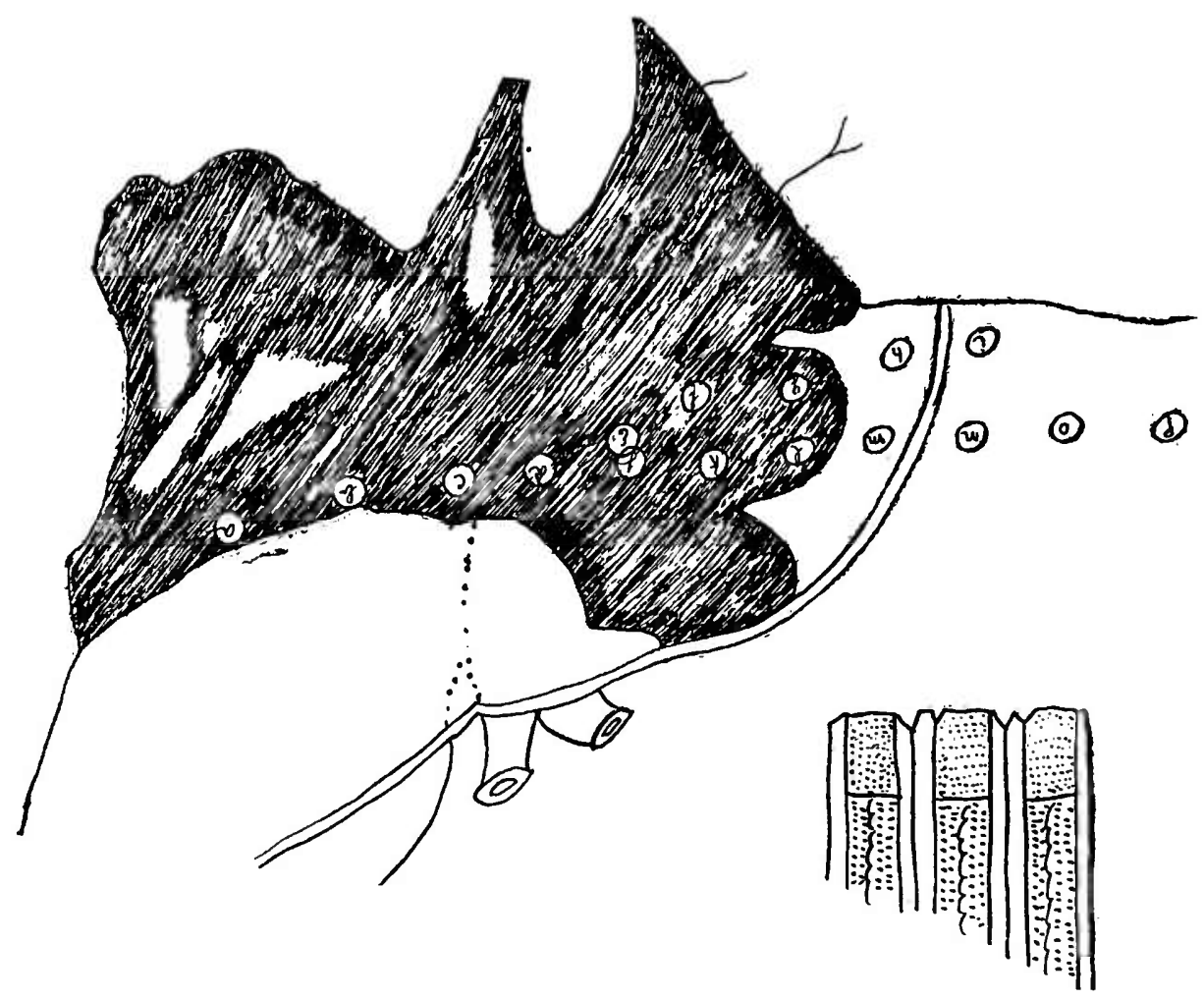

N. 5

meiras, como o seu nome indica, são derivações tomadas directamente sobre o musculo cardiaco; as dọ segundo grupo dizem respeito a derivações. tomadas em pontos affastados do coração aproveitando-se para isso da direcção do eixo electrico das correntes desenvolvidas no coração. Esse novo methodo, a que atraz fizemos referencia, é o electrocardiographico, que como o seu nome indica, é o registro das correntes electricas formadas pela contracção do musculo cardiaco. As curvas electricas dos batimentos cardiacos exibem uma consideravel constancia de animal para animal da mesma especie e mesmo entre alguns de especies differentes. Assim por ex:, entre o electrocardicgramma do homem e do cão. 
A semelhança das curvas nos está a indicar identidade na situação topographica do "pace-maker" Portanto as conclusões que tiraram para o cão nas exper:mentações servirão para o homem. Do mesmo modo, se com-

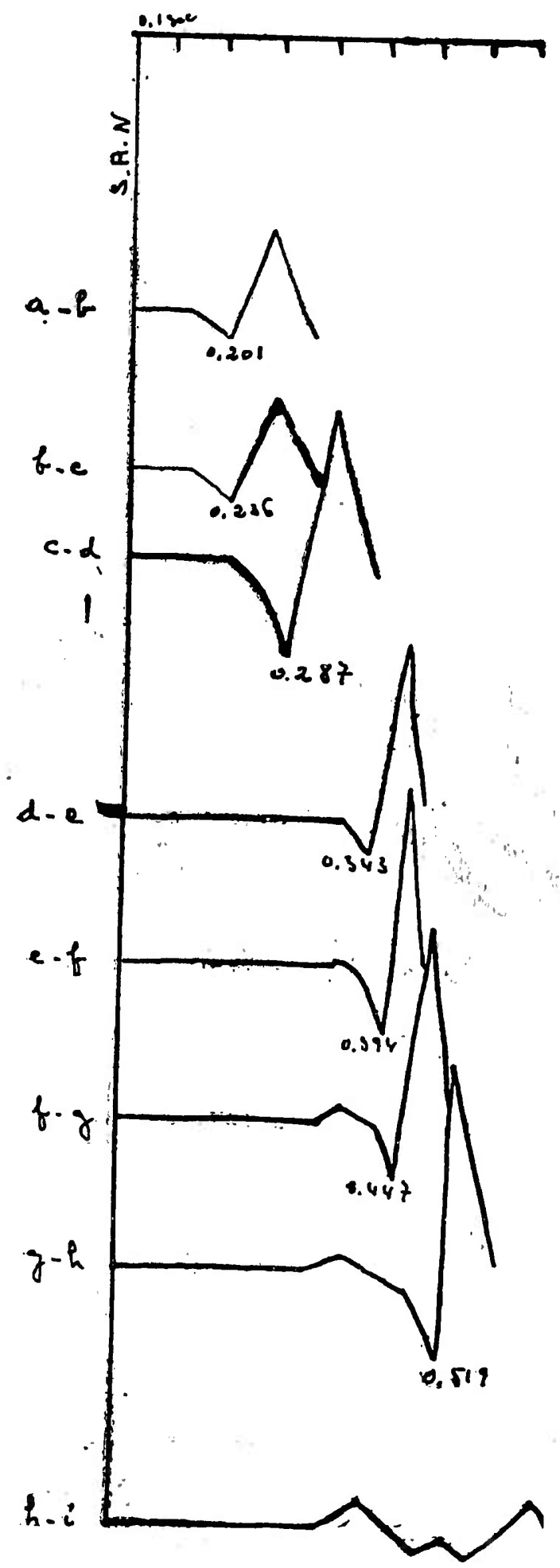

N. 6 
pararmos as curvas obtidas por excitação directa da auricula do cão, com as curvas obtidas pela contracção normal do coração do cão, veremos que as curvas serão semelhantes todas as vezes que o contacto $\mathrm{Z}$ (primeiro. ponto a se tornar megativo) estiver collocado nas visinhanças da veia cava superior. E' portanto para esse ponto que devemos centralizar as nossas observações. "Para determinarmos o "pace-maker" devemos conhecer o primeiro ponto a se tornar negativo, que se revela por uma deflexão para cima desde que ahi esteja localisado o contacto Z. Para isso tomamos

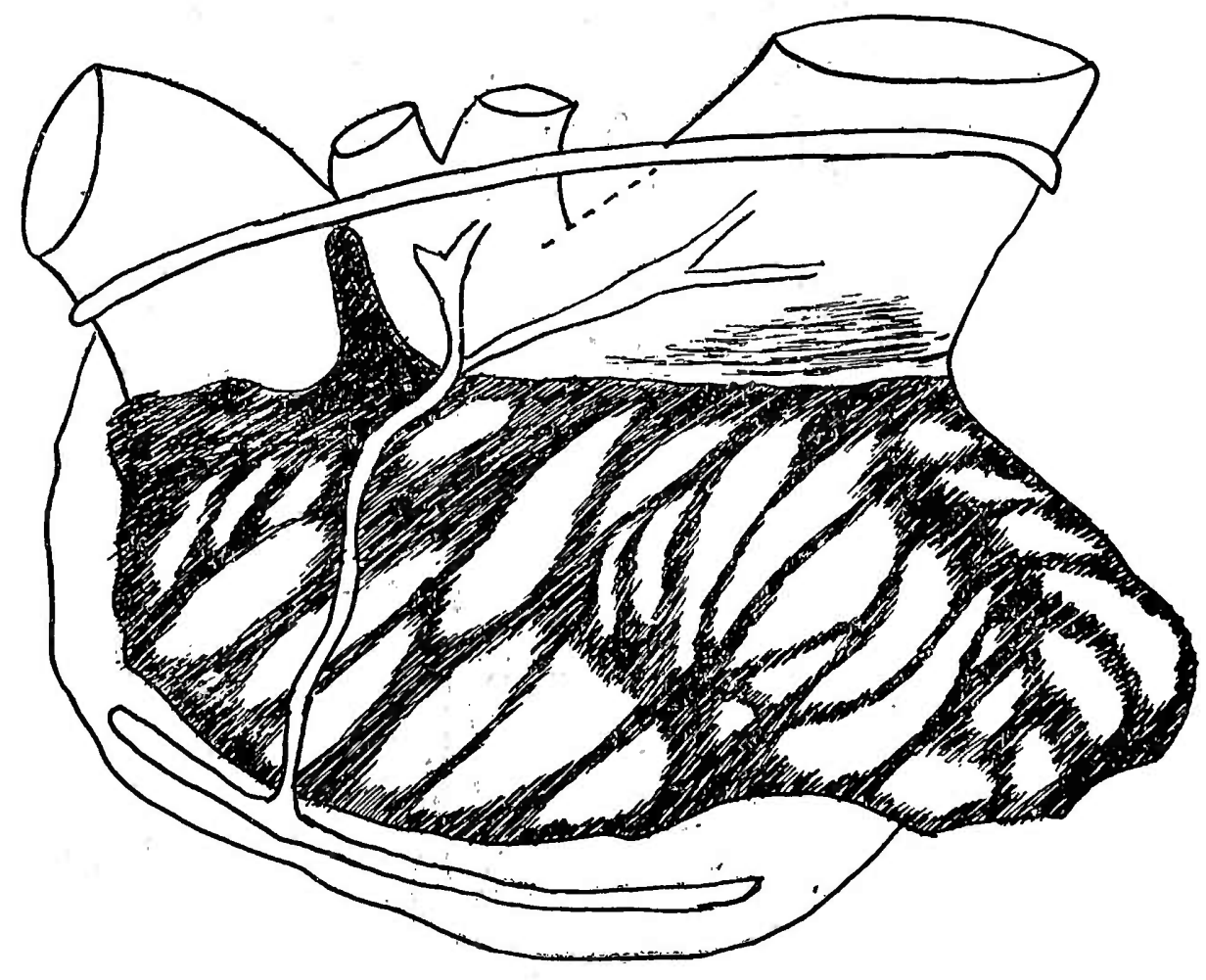

N. 7

uma serie de derivações directas sobre a auricula e comparando-as com as derivações indirectas veremos que é sempre o nodulo sinus auricular (N. S. A.) o primeiro a se tornar negativo. 'Para melhor elucidação poderemos collocar oelectrodo Z no N. S. A., e circumdando esse ponto, differentes electrodos C. Registrando essas curvas veremos que todas exibem primeiro uma deflexão para cima indicando que o ponto primitivamente negativo foi o correspondente ao contacto $\mathrm{Z}$ como poderemos vêr no eschema n. ${ }^{\circ}$ 2. Se no sulcus terminalis, para mais apurada localisação, 
collocarmos os electrodos ligando o ponto T2 aos pontos T3, T5 e T7, o primeiro proximo á veia cava superior e o ultimo da véa cava inferior, como nos mostra o eschema $n .^{\circ} 3$, veremos, se o electrodo $Z$ estiver em $\mathrm{T} 2$, que nos tres casos obtemos deflexões para cima identicas á elevação $P$ do electro cardiogramma normal em derivação II, que deixa melhor perceber $o$ accidente auricular. Isso vem nos provar, além da identidade deste "pace-maker" que a onda de excitação iniciada em T2 passa successivamente pelos pontos T3, T5 e T7. Podemos ainda estudar a localisação do "pace-maker" pelo estudo comparativo das deflexões intrinsecas e extrinsecas. Chamamos deflexões intrinsecas as oscillações para cima obtidas pela chegada da onda de excitação ao ponto estudado. Chamamos

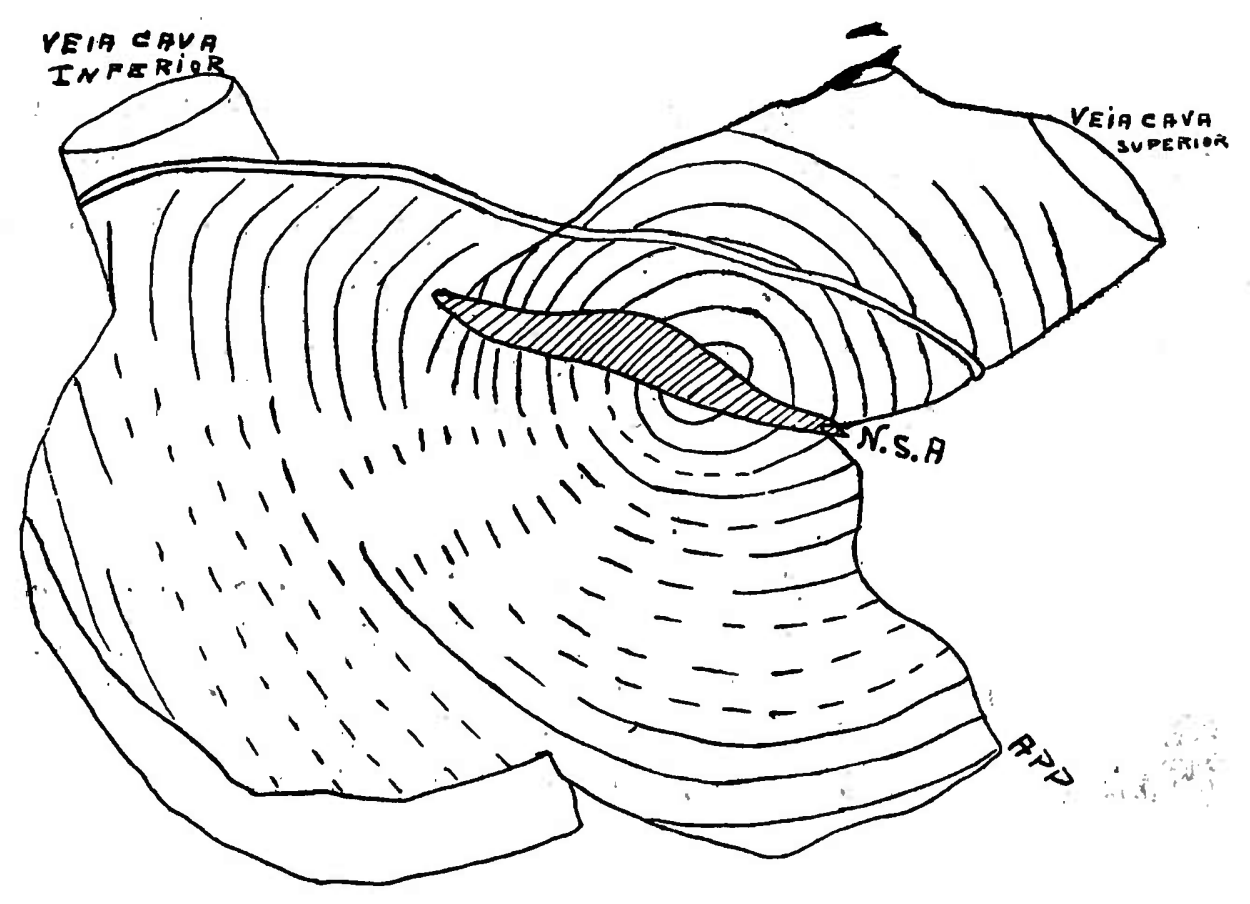

N. 8

deflexões extrinsecas as oscillações para baixo indicando a passagem da excitação em um ponto visinho ao estudado. Assim se compararmos as curvas obtidas com derivações directas, com as obtidas em derivação II (indirecta), veremos que só obtemos deflexões intrinsecas, semelhante e simultaneas ao $\mathrm{P}$ da derivação $\mathrm{II}$, quando o contacto $\mathrm{Z}$ estiver mo N. S. A.; do contrario iremos obter deflexões extrinsecas coincidindo com a elevação $P$ e em seguida uma deflexão intrinseca indicando a chegada da onda. Ainda podemos determinar o "pace-maker" ou pela destruição do N. S. A., ou excitando esse ponto pelo frio ou pelo calor. Sabemos que o 
frio diminue e o calor augmenta o numero dos batimentos cardiacos; pois bem, esses excitantes só serão efficazes quando levados directamente ou N. S: A. Nenhum effeito será obtido quando levados a outros pontos.

Conhecida e provada a existencia de um "pace-maker" nos mamm:feros, passemos a estudar o modo pelo qual a onda de excitação e de contracção se propaga as outras partes da auricula. Para isso usamos derivações directas tomadas em differentes pontos da auricula como nos mostra o eschema n. ${ }^{\circ} 4$ (contacto $\mathrm{Z}$ no $\mathrm{N}$. S. A.), e comparando as curvas obtidas com o electrocardiogramma em derivação II, podemos, pelo apparecimento das deflexões intrinsecas, marcar o tempo da chegada da excitação a cada um dos pontos estudados. Podemos ass.m mostrar que a. onda se propaga radiadamente do N. S. A. em todas as direcçóes. Pelo estudo dos eschemas n.os 5 e 6 poderemos vêr que a onda se propaga atravez as fibras musculares. Assim, se no eschema.$^{\circ}$ 5, ligarmos dois a dois os pontos assignalados, por electrodos não polarizaveis, a um galvanometro, veremos que uma vez excitado o N.S. A. a onda se propaga aos differentes pontos, sendó a sua chegada assignalada por um deflexão intrinseca como poderemos vếr no eschema n..$^{\circ}$. No mesmo eschema além do tempo de apparecimento de deflexã́o intrinseca, veremos, precedendo a

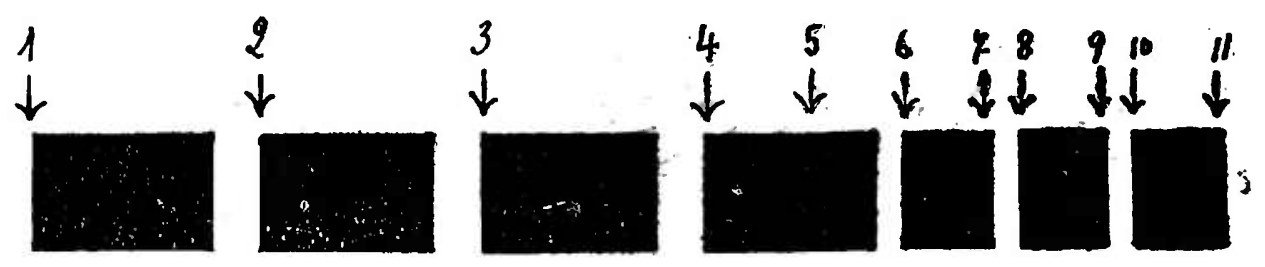

deflexão intrinseca, uma deflexão extrinseca que nos indica a existencia de um ponto anteriormente excitado. Ainda nesses dois eschemas veremos, que uma vez desapparecidas as fibras musculares, - contactos $\mathrm{H}$ e I cessa a propagação da onda de excitação. Desse mcdo pcideremos vêr que a onda de excitação nascida no N. S. A. se propaga como se fora um liquido collocado em uma superficie lisa e chata, isto é, formando ondas 'cadia vez mais largas, para o que a distribuição das fibras musculares' está adaptada, como nos mostram os eschemas n.os 7 e 8: Além de conhecer o modo de propagação, pelo conhecimento da distancia entre um e outro pontos, poderemos medir a velocidade de propagação da onda de excita- 
ção, que é na media $1.000 \mathrm{~mm}$. por segundo, havendo no entanto variações de uma região para outra, coimo poderemos vêr no seguinte quadro:

\begin{tabular}{|l|r|r|r|}
\hline \multicolumn{1}{|c|}{ REGIÕES } & $\begin{array}{r}\text { Distancia } \\
\text { em mm. }\end{array}$ & $\begin{array}{c}\text { Transmissão em } \\
\text { segundos }\end{array}$ & $\begin{array}{c}\text { Velocidade em mm. } \\
\text { por segundo }\end{array}$ \\
\hline \hline Região entre as cavas & 15,2 & .0139 & 1232 \\
Fita inter-ạuricular & 12,9 & .0126 & 1252 \\
Veia cava superior & 8,2 & .0136 & 588 \\
Septum & 31,5 & .0305 & 1059 \\
Appendice direito & 28,0 & .0314 & 955 \\
Auricula direita & 16,0 & .0206 & 859 \\
Veia pulmunar direita & 24,0 & .0254 & 1121 \\
Veia cava inferior & 31,5 & .0325 & 998 \\
Seio coronario & 43,9 & .0412 & 1096 \\
Veia pulmonar esquerda & 45,2 & .0412 & 1118 \\
Appendice esquerdo & 44,6 & .0446 & 996 \\
\hline
\end{tabular}

Ainda, para bem comprehendermos o assumpto de nossa palestra, necessitamos conhecër o que significa periodo refractario. E' sabido que um musculo é refractario a uma nova excitação durante um certo periodo de tempo após a sua contracção. A isso denominamos periodo refractario, podendo ser absoluto ou relativo. E' absoluto quando nenhum excitante é capaz de o estimular; é relativo, quando uma excitação mais forte que a anterior é capaz de o estimular. Quando daqui por diante fallarmos em periodo refractario, queremos' nos referi ao periodo de refractibilidade absoluta. E' sabido que o coração augmentando o numero de batimentos, esse augmento se fará a custa de um encurtamento da diastole, em grande parte, e da systole em pequena parte. Portanto o periodo refractario tambem se encurtará. Porém esse encurtamento da diastole, da systole e do periodo refraçtario é limitado. Haverá um ponto em que não é mais possivel ao coração responder á todas as excitações: haverá então rythmos $2: 1,3: 1$, $4: 1$ etc. Assim se o coração batendo a 200 por minuto, durando todo o cyclo 0,30 de segundo e sendo o periodo refractario egual a 0,14 de segundo, se esse rythmo augmentar bruscamente para 550 , a primeira excitação cahirá a 0,11 após a ultima excitação e se'á ineficaz. Ficará desdé então estabe- 
lecido o rythmo a $2: 1$ como nos mostra o eschema n." 9, onde as excitaçães, $5,7.9$ e 11 não são proveitosas. Poderemos ainda, nesse mesmo eschema, verificar a diminu:ção do periodo refractario. Se ao contrario o rythmo augmentar lentamente, haverá tempo para um maior encurtamento da diastole, da systole e dio periodo refractario e não se estabelecerá o rythmo a2 : 1 sinão quando elle se tornar muito frequente, havendo dois estados intermediarios (alternancia e phase irregular) como veremos no eschema n. ${ }^{\circ}$ 10. Para comprehendermos á alternanc:a devemos ter noção do que acontece na phase de refractibilidade relativa. Nessa phase o

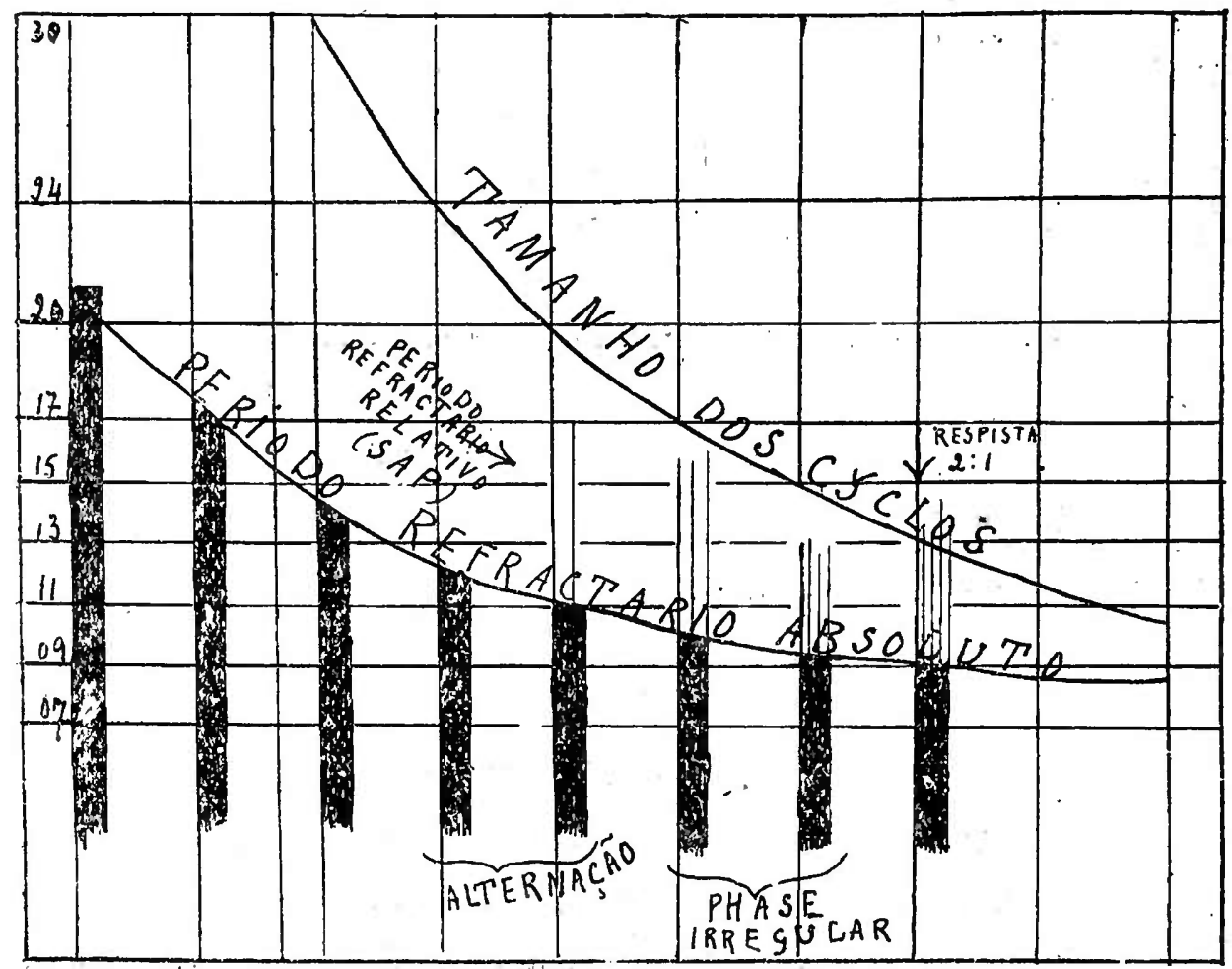

N. 10

musculo só responderá a estimulos energicos e num periodo mais adiantado dá refractilidaide relativa, sómente um certo numero de fibraśs será excitado, dando em resultado alternaricia na força dos batimentos, como poderemos vêr no eschema $n \cdot^{\circ} 11$, excitações id e e. Quando estudamos num feixe muscular a velocidade de condução, teremós, nessa phase, a impressão de uma menor conductibilidade. No entanto, esse facto nada mais é que o resultado da refractibilidade relativa. $\mathrm{O}$ estimulo procura fibras excitaveis para percorrer, dando em resultado um trajecto sinuoso 
em logar de rectilineo, como podemos ver no eschema n. 12. Se relacionarmos, o que acabamos de estudiar á auricula, veremos que antes de apparecimento do rythmo a $2: 1$ teremos alternancia na amplitude das deflexões, indicando um menor numero de fibras excitadas, bem como uma perturbação na condução do estimulo comọ já foi visto no eschema n. ${ }^{\circ} 12$.

Feitas essas considerações geraes, poderemos passar ao estudo do movimento circular.

Foram Mayer e Mines os primeiros que, usando anneis musculares da auricula de um peixe provaram que o estimulo levado sobre elle, deside lque fosise ccntinuo, era capaz de circular continuadamente originando o rythmo circular fundamnital. Vejamos o que se obtem nos anneis musculares quando excitados por simples choque die inducção, isto é, excitação

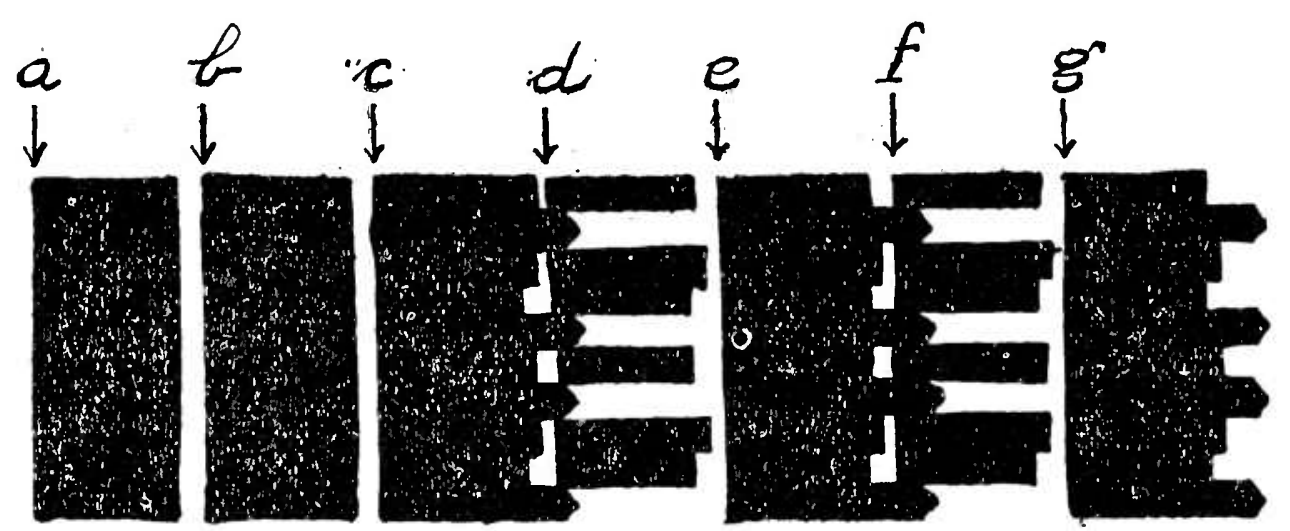

N. 11

não continua. Se nessas condições, excitarmos um annel muscular em um ponto, o estimulo de excitação e de contracção se propaga em ambas as direcções em torno ao annel como poderemos vêr no eschema n. ${ }^{\circ} 13$. Assim a onda nascida em $a$ se propaga em torno ao annel até attingir o ponito $b$ em posição symetrica ao ponto $a$. Representando em preto o periodo refractario veremos que no crirculo $I V$ do eschema todo o anmel se tornou refractario. Uilteriormente o annel vae rovamente se tornar excitado, pelo desapparecimento progressivo da phase refractaria que se processará na ordem de seu apparecimenio. Ajoós isso é novamente o annel excitado no mesmo ponto $a$, repetindo-se todas as phases da excitação anterior. Imaginemos que na phase VI do eschema n.' 13, uma nova excitação seja levada sobre o ponto $a$; teremos então uma nova onda de excitação percorrendo o annel como nos mostra o eschema n. ${ }^{\circ}$ 14. Essa nova onda de 
excitação precederá sempre a primeira de um mesmo intervallo de tempo dado pelo periado refractario. $E^{\prime}$ isso que normalmente observamos em torno á desembocadura da veia cava superior. Se a frequencia de excitação augmentar-a ponto de uma excitação encontrar o annel em phase refractaria teremos um rythmo a $2: 1$ e proseguindo poderemos têr a $3: 1,4: 1$ etc. Se a um annel muscular levarmos uma excitação de maior frequencia

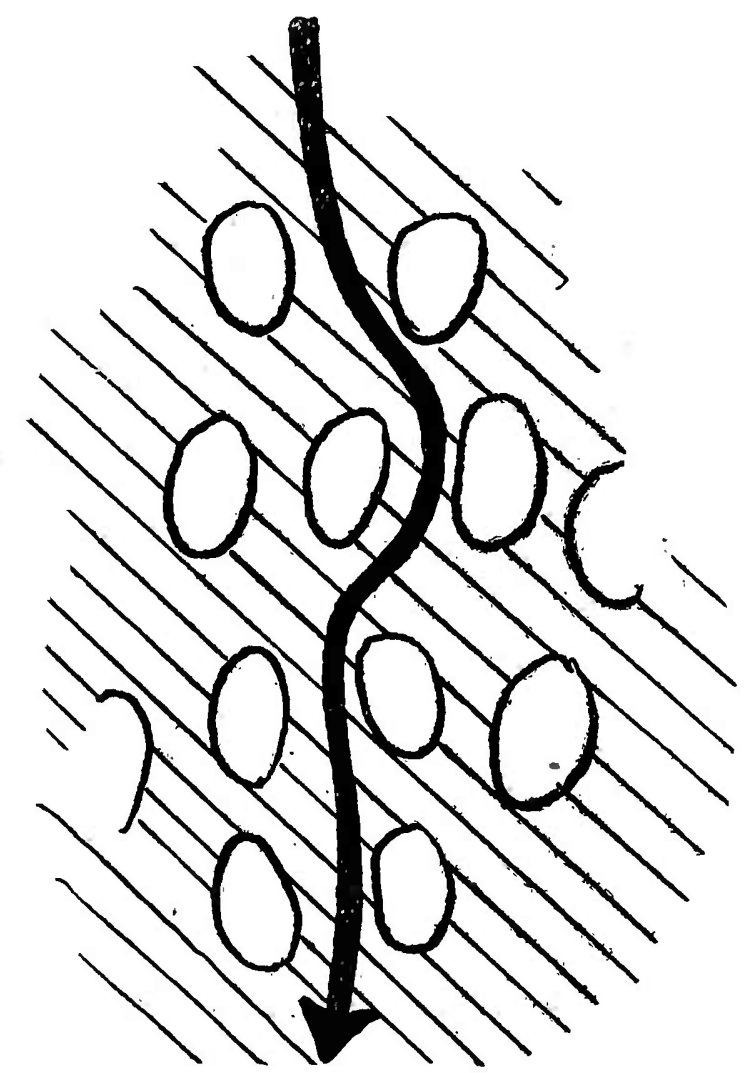

N. 12

ou mesmo continua, havendio de um lado fibras em grande numero ou em totalidade em phase refractaria, e de outro lado grande numero de fibras excitaveis, a onda só se propagará de um lado. Proseguindo o seu caminho como nos mostram os anneis do eschema n. 15, a onda vem têr ao seu ponto de origem. Por esse tempo já o musculo nessa região readquiriu a sua excitabilidade; a onda proseguirá, repetindo o trajecto anterior, e assim continuará indefinidamente. Essa onda circulante é, como já devemos prever, governada por tres factores interdependentes: 
1. ${ }^{\circ}$ : - Tamanho da annel muscular;

$2 . .^{\circ}$ : - Tempo que a onda leva a percorrel-o;

3. ${ }^{\circ}$ : - Duração do periodo refractario do ponto primitivamente excitado.

Se uma onda, originada em um ponto de um annel muscular, se propagar sómente em uma direcção, uma vez chegada ao seu ponto de origem, ella só proseguirá se o encontrar excitavel. Portanto o periodo réfractario tem forçosamente que durar menos que o tempo que ella leva para atravessar todo o annel. Ora, o tempo que a onda leva para percorrel-o depende:

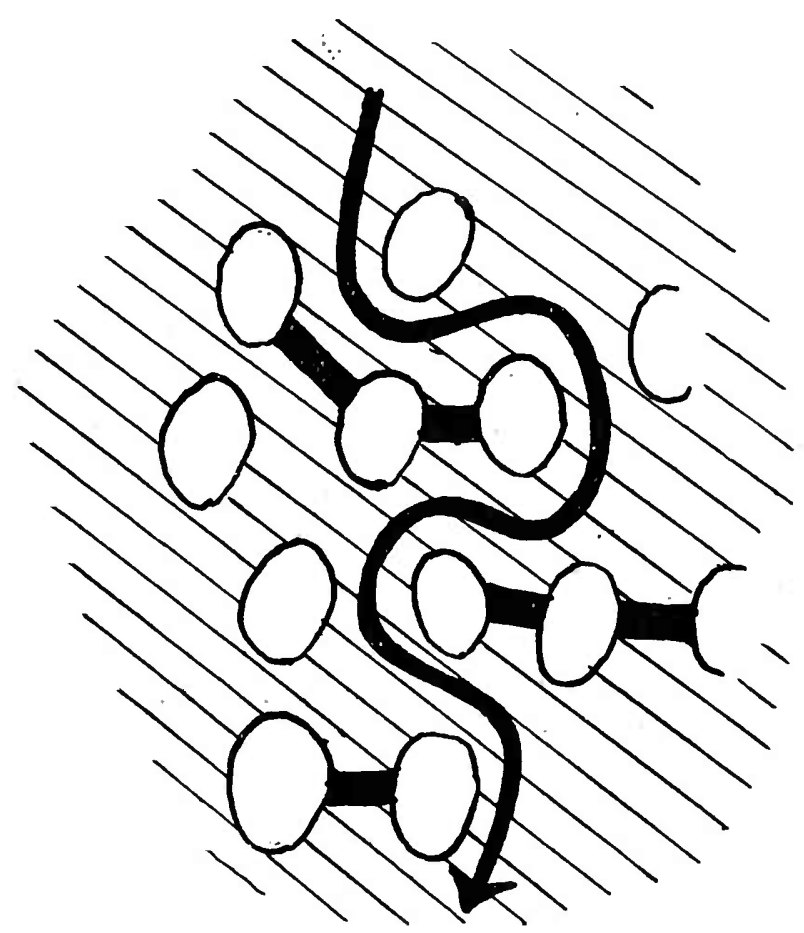

N. 13

1.`: - Do tamanho do annel;

2.: - Da velocidade de condução.

Assim se um annel med:r $100 \mathrm{~mm}$., se a velocidade fôr de $500 \mathrm{~mm}$. por segundo, a onda levará 0,20 de segundo para atravessal-o. Se o periodo refractario durar 0,15 , haverá um espaço de 0,05 de segundo entre o fim do periodo refractario e a chegada da excitação; a isso chamaremos - como os inglezes — "Gap" isto é, o per:odo de tempo em que as fibras inicialmente excitadas já deixaram de ser refractarias e ainda não 
foram alcançadas pela onda de excitação circulanté. Portanto, quanto maior fôr o "Gap" tanto mais facilmente se estabelecerá o rythmo circular. Assim sendo os factores que favorecem o rythmo c.rcular, ou que tendem a augmentar o "Gap" são:

1.' - Annel longo.

$2 .^{\circ}$ : - Lenta velocidade de conducção

3. : - Pequeno periodo refractario.

Inversamente, os factores que difficultam o rythmo circular, ou que tendem a diminuir o "Gap" ou mesmo a fezl-o desapparecer, são:

1.. ${ }^{\circ}$ - Annel curto

2. - Vieloz conducção.

3.' - Grande periodo refractario.
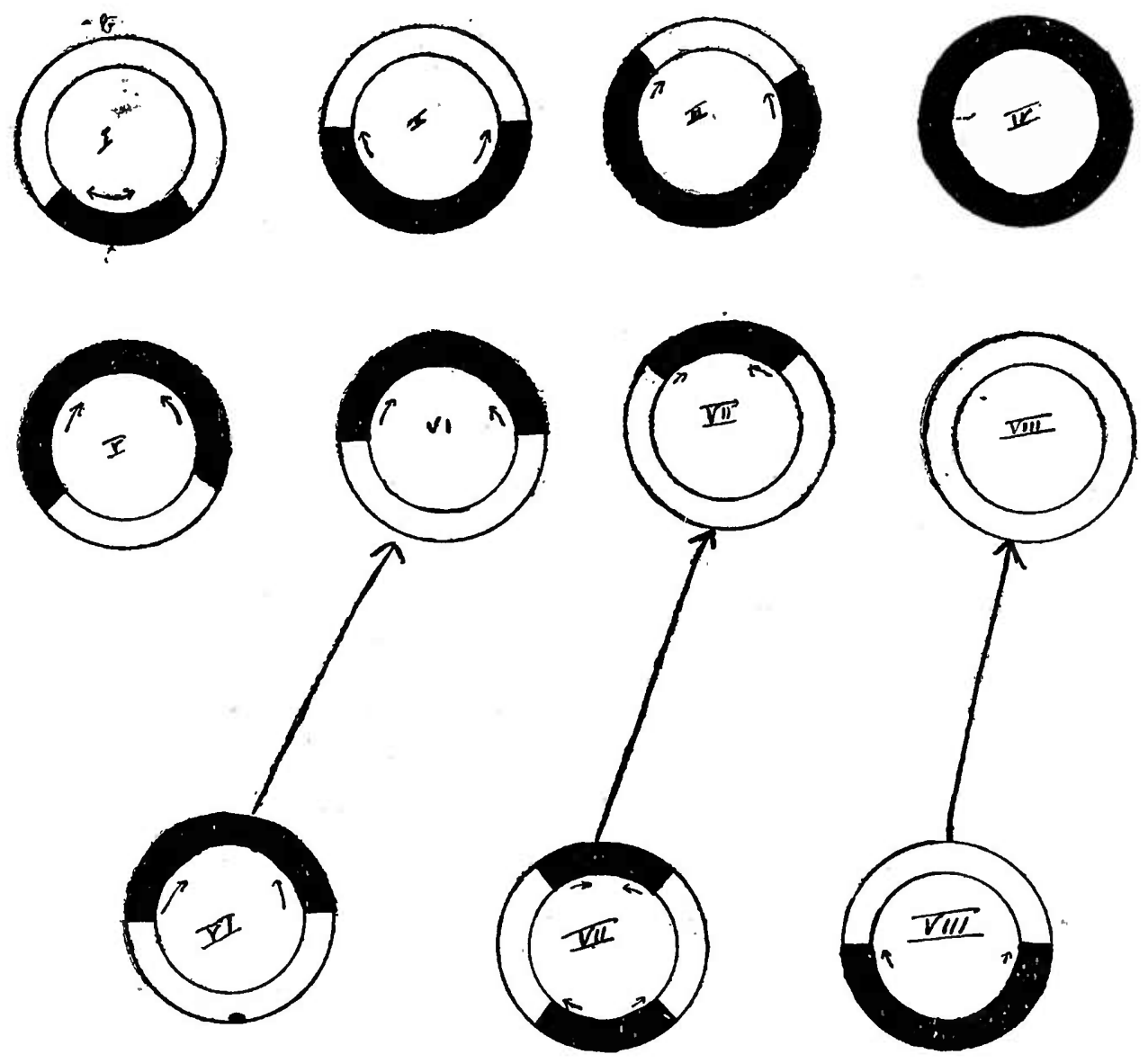

N. 14 
A frequeccia de batimentos é dada pelo tempo que a ondia leva para percorrer todo o annel. Assim, se para o caso formulado, foi 0,20 de segundo, teremos 300 circuitos ou 300 batimentos por minuto.

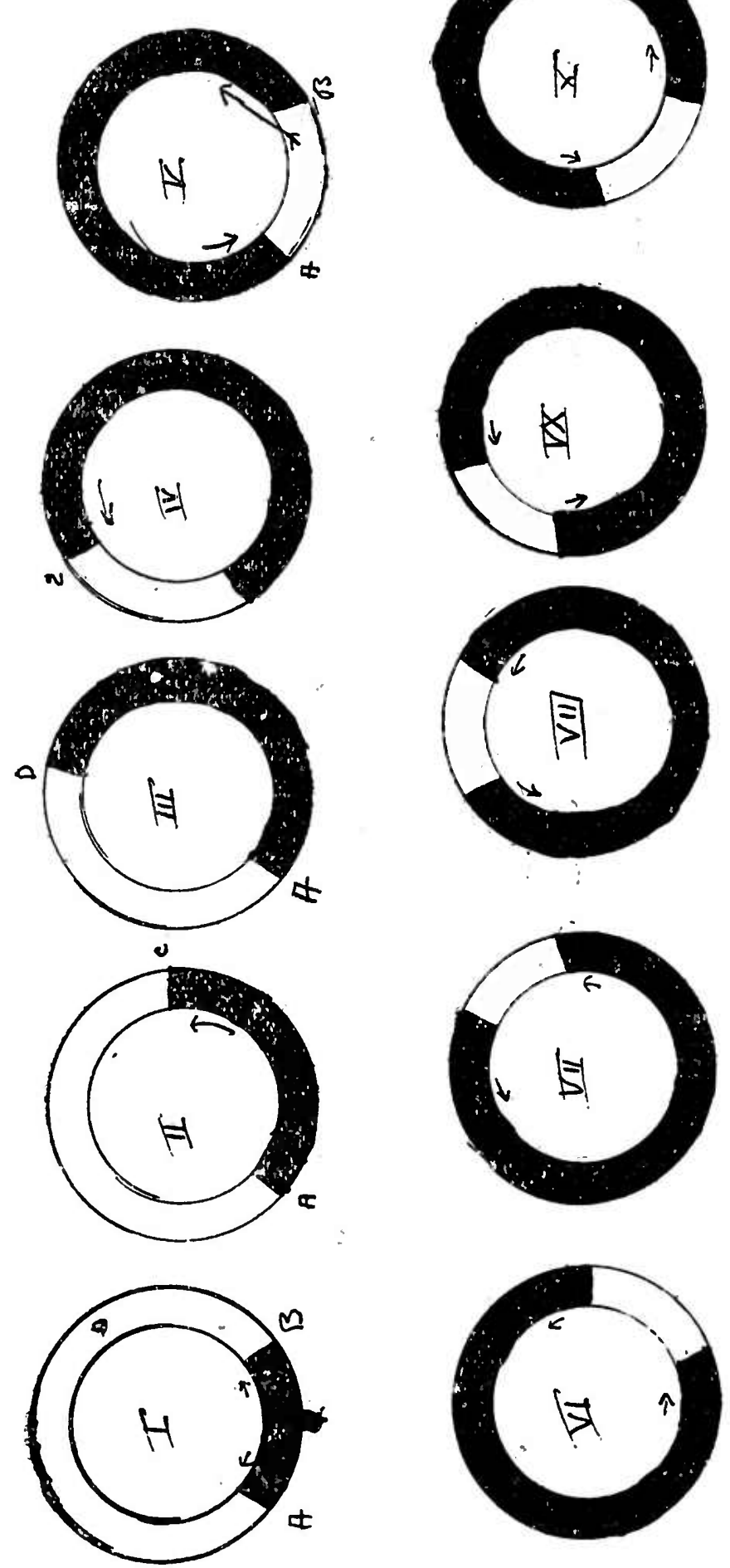

N. 15 
Uim annel muscular, simples, pequeno, perfeitamente delimitavel, como o que foi objecto de nossa descripção, não o encontramos na auricula. Ahi encontramos anneis musculares naturaes como os que envolvem
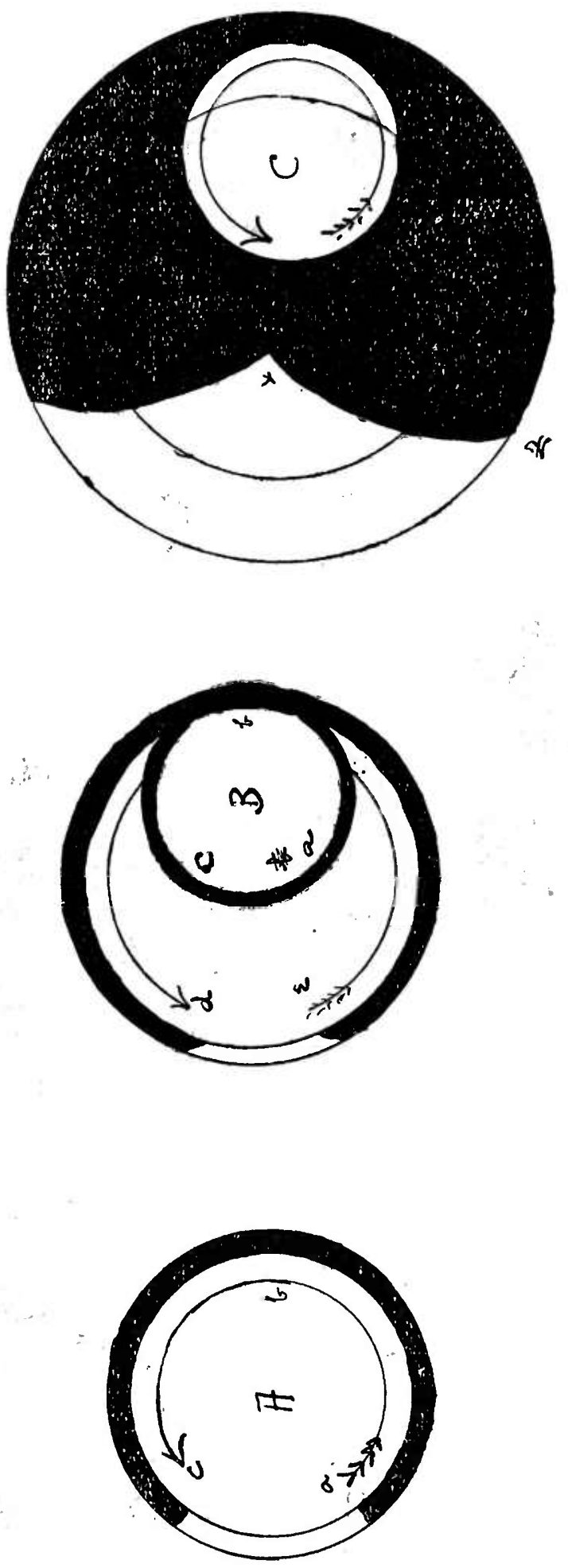

N. 16 


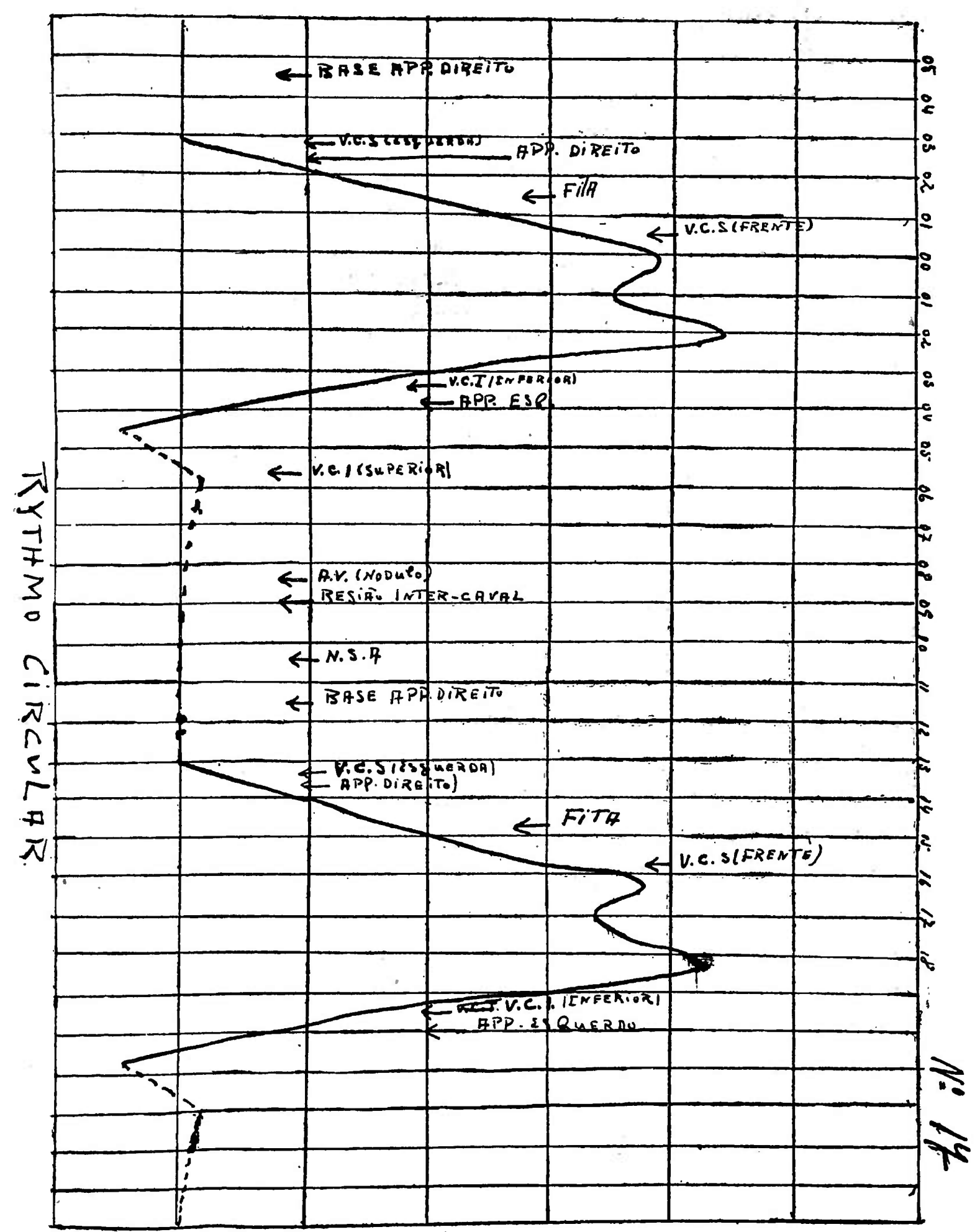

N. 17 
os orificios das grandes veias e o orificio auriculo-ventricular. Circundado esses anneis, mais exteriormente, temos uma iserie immensa de optros anneis, que em occasião opportuna poderão cervir de conductores á onda de excitação. Se estudarmos o eschema $n .^{\circ} 16$, veremos um primeiro annel, A onde é possivel o rythmo circular. Se por circunstancias que pana o caso presente não importa quaes sejam, o periodo refractario $a b c$ augmentar, fazendo desapparecer o "Gap", veremos a onda procurar um annel mais externo, afim de que para um mesmo periodo refractario. e uma mesma velocidade de onda ainda existe "Gap" o que quer dizer, ainda seja possivel o movimento circular. E' o que poderemos observar no eschema n. ${ }^{\circ} 16$ figuras $I I$ e $I I I$. Nesse caso,, podendo variar o percurso de onda para onda, não podemos calcular por seu intenmedio a frequencia dos batimentos. Portanto, não se podendio individualisar o trajecto seguido pela onda, o unico criterio que temos para calcular sua velocidade é o tamanho do periodo refractario.

Se levarmos scbre a auricula de um cão uma forte e continuadia excitação por meio de uma corrente farádica, veremos que ella apresentará pelo espaço de 20 a 30 minutos, um movimento circular. Isto é, em lugar da onda nascer no N. S. A. e se espalhar radiadamente como normalmente, ella, nascida em um ponto, circulará indefinidamente. Não ha mais nesse caso um ponto de origem; a onda circulará continuadamente. Se nesse caso registramos o electrocardiogramma, não mais veremos a elevação $P$, reveladora da actividade auricular, mais uma serie de pequenas elevações, iguaes em altura e em intervallo de uma para outra. Não ha portanto a contracção em massa de toda a auricula mas sim a contracção isolada de feixes de fibras. A prova da veracidade dessa as. serção é dada pelas derivações directas tomadas na auricula desse cão. Tomamos diversos pares de derivações, em differentes posições e os registramos simultaneamente. Pelo conhecimento das deflexões intrinsecas poderemos conhecer os pontos tornados excitados e desse modo conhecer do percurso da onda. ' $E$ ' isso que poderemos vêr nos eschemas a.os 17. 18, 19 e 20. No "caso figurado, o movimento circular se processa em torno ao annel das cavas, podendo, no entanto, se estabelecer em qualquer outro annel, com por ex. em torno a o orificio mitral. Para - mosso caso, a onda nascendo na veia cava inferior pessa pelo IN S. A., veia cava superior contornando-a, volta novamente ao 
seu ponto de origem passando pela parte inferior da veia cava inferior, fechando então o circulo. Por todos os pontos por onde passa a onda a excitação é distribuida ás fibras dessa região, que entra em contracção, originando a serie de pequenas elevações $\mathrm{P}$ do electrocardiogramma. A onda mais interma denominaremos de onda mãe $\mathrm{e}$ as ondas provenientes das descargas das excitações nos diversos pontos da onda mãe, chamaremos de ondas centrifugadas.

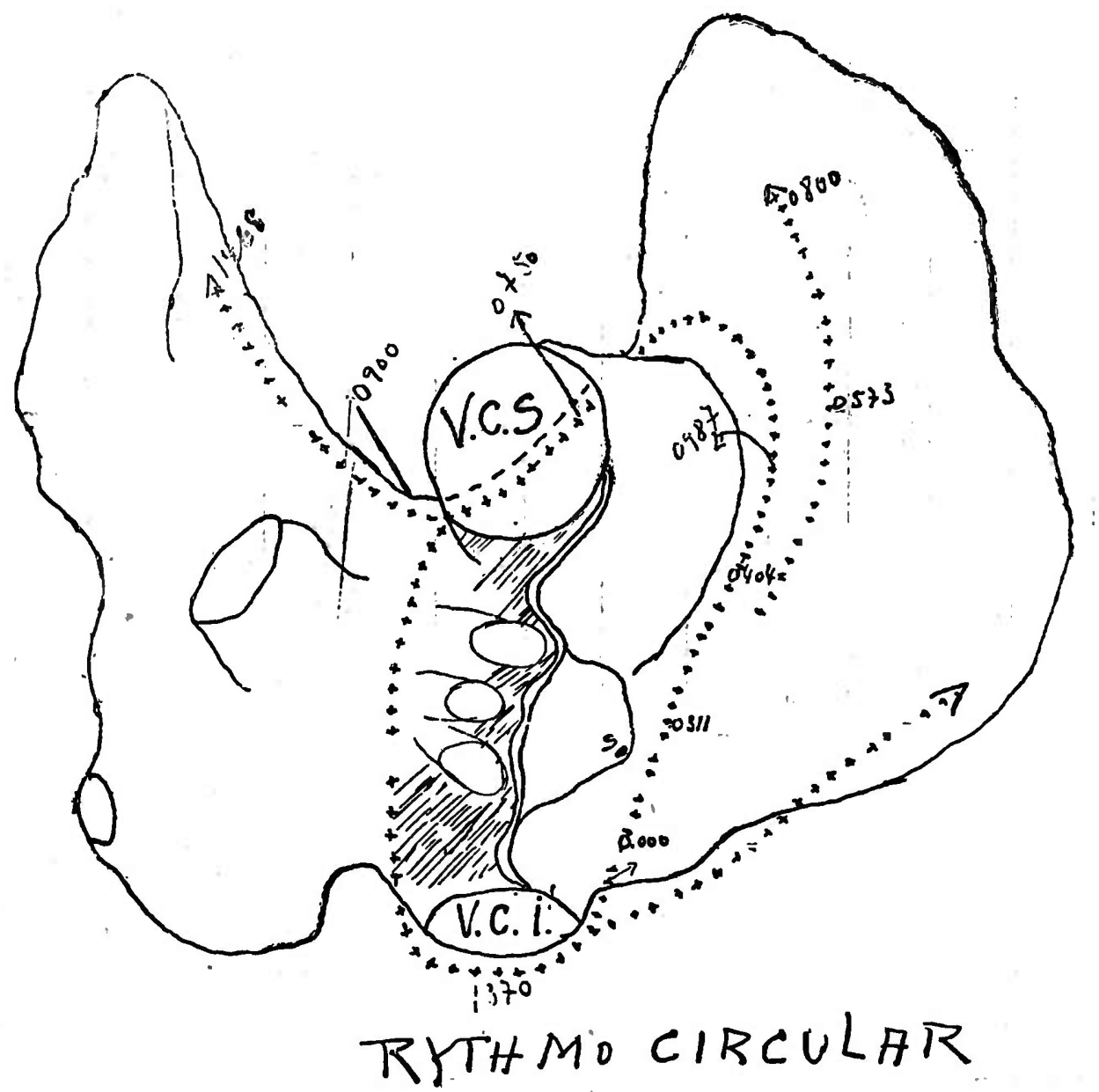

N. 18

Quando na auricula do homem apparece anormalmente um ponto mais excitavel que o N. S. A.., e que pela frequencia maior de excitaçōes sobrepuja o nodulo, poderemos vêr o apparecimento do que acabamos de estudar no cão quando provocamos artificialmente o apparecimento desse ponto. Instituido o rythmo circular na auricula do homem teremos 


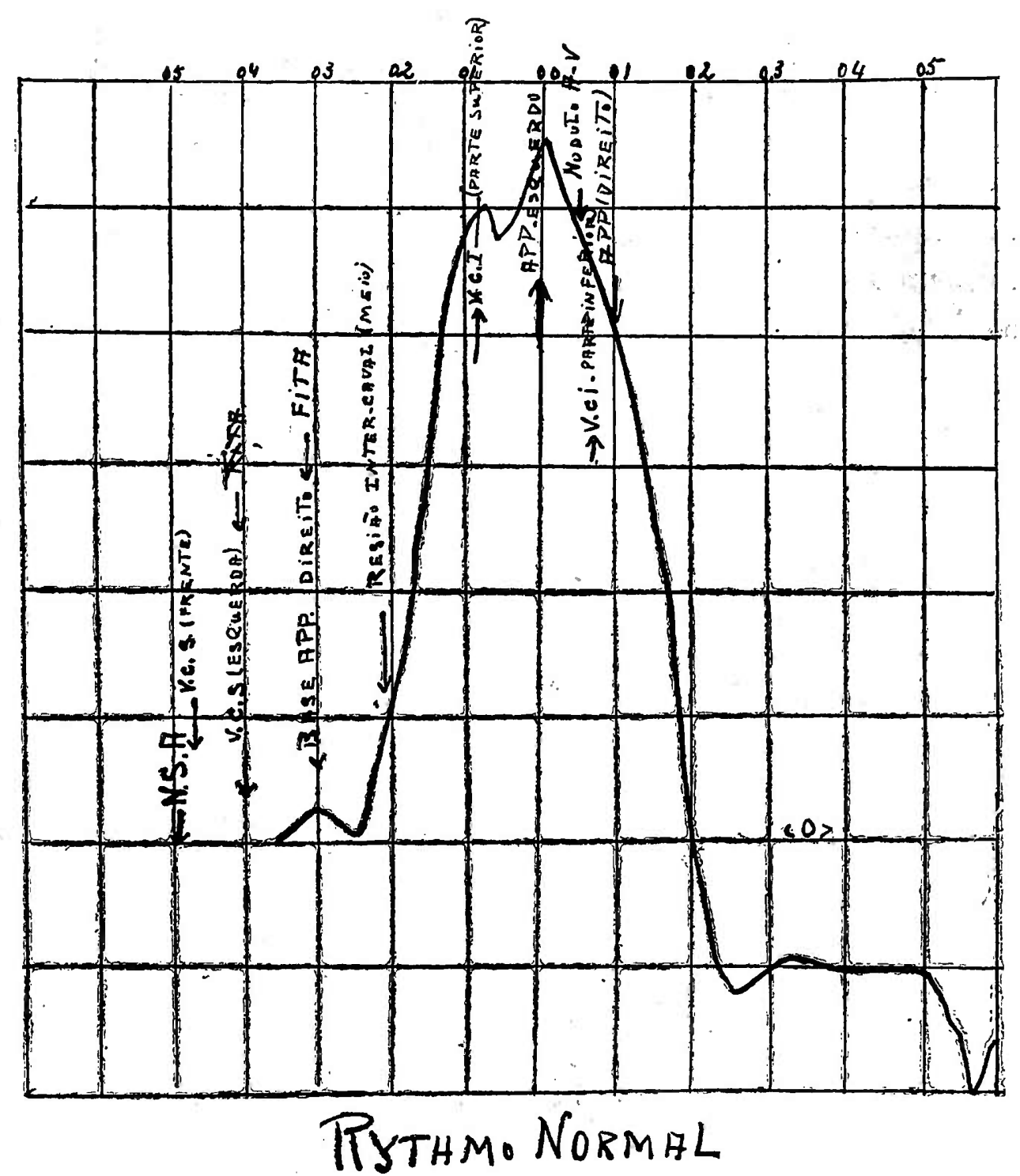

N. 19

duas entidades morbidas - "AURICULAR FLUTTTER" ou Tachy-systolia auricular, e a FIBRILAÇÃO AURICULAR. Na "AURICULAR FLUTTER" ha regularidade no trajecto seguido pela onda de excitação de cyclo para cyclo, o que explica a regularidade na amplitude e nos intervallos das pequenas oscillações $P$ do electrocardiogramma. Ainda póde se distinguir uma "FLUTTER" pura e outra impura, dependendo isso da maior ou menor regularidade das oscillações P. Na FIBRILAÇÃO AURICULAR observamos justamente o inverso. Ha ccmpleta irregularidade no trajecto da onda de excitação. No electrocardiogramma. não mais encontramos a elevação. $P$, nem tam- 
pouco as "elevações pequenas e regulares da "FLUTTER" Vamos encontrar um cerrilhado irregular em amplitude e em intervallo. $E$ ' a irregularidade levada ao maximo. Qual a causa dessa differença? Podemos compreender perfeitamente pelo estudo do eschema n.' 21. Nesse es-

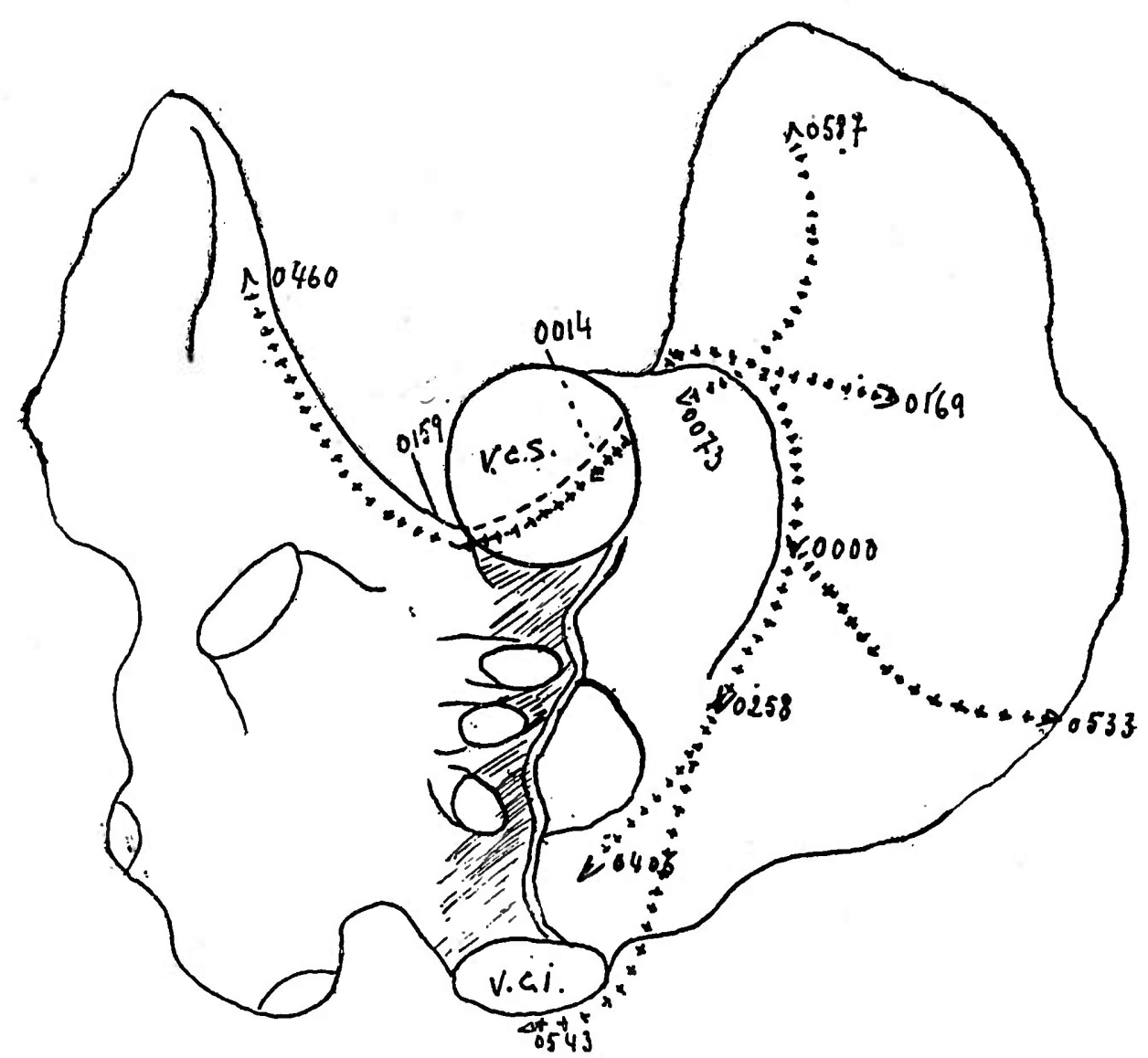

RYTHMU NDR.MAL

N. 20

chema a phase refractaria é representada em branco e em preto a phase excitavel. No primeiro circulo a ésquerda veremos que a onda de excitação ao completar o trajecto encontra um grande numero de fibras excitaveis, podendo por isso continuar o mesmo trajecto anterior, o que expl:ca a igualdade nos intervallos de uma á outra elevação $\mathrm{P}$. Além disso havendo grande numero de fibras excitaveis a amplitude das oscillações $P$ não varia ou se variar é pequena a differença. No circulo á direita veremos que a onda de excitação encontra em seu ponto origina- 
rio um pequeno numero de fibras exctaveis, o que nos explica a differença de amplitude. Outras vezes sendo muito reduzido o numero de fibras excitaveis ou não as havendo, a onda de excitação, cconforme o eschema $n^{\circ} 12$, procura um trajecto mais. exterior, para no circulo seguinte, haverndo grande "Gap" percorrer um circulo mais interno, o que vem nos explicar além da differença de amplitude, a differença nos intervallos entre uma e outra elevação. Poderemos provar experimentalmente o que acabamos de relatar usando pares de electrodos seriados em toda a auricula, e pelo comhecimento das deflexões intrinsecas e extrinsecas" conhecer o trajecto da onda de excitação de cyclo para cyclo.

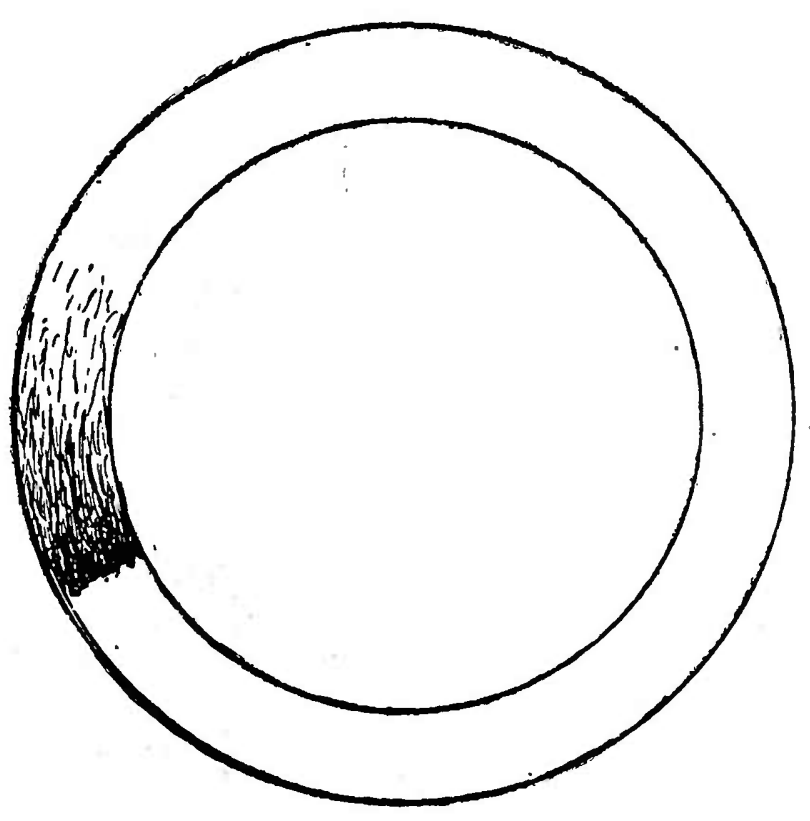

N. 21 a

Tanto a "FLUTTER" como a FIBRILAÇÃO AURICULAR trazem rythmos muito elevados, podencio-se attingir a 1.000 rotações por minuto ou mesmo mais. $\mathrm{Ha}$ portànto passagem quasi in nterrupta de excitações da auricula para o ventriculo. E' claro que nem todas serão proveitosas devido ao periodo refractario ventricular. Sabemos que quando o numero de excitaçóes augimenia, o ventriculo procurando satisfazer a todas, encurta a sua diastole, em grande parte, a sua systole em pequena parte, e o seu periodo refractario. Porem esse encurtamento chegando ao maximo, elle não poderá mais satisfazer a todas as excita- 
ções, teremos entã̃o os rythmos a $2: 1,3: 1,4: 1$ etc. Na "FLUTTER" havendo regularidade das excitações, notamos tambem regularidade nas respostas ventriculares, tamto em amplitude como em intervallo de uma para outra.

$\mathrm{Na}$ FIBRILA-

ÇÃO AURICULLAR, devido a irregularidade ao maximo das excitações, tambem notarmos completa irregularidade para o lado dos ventri-

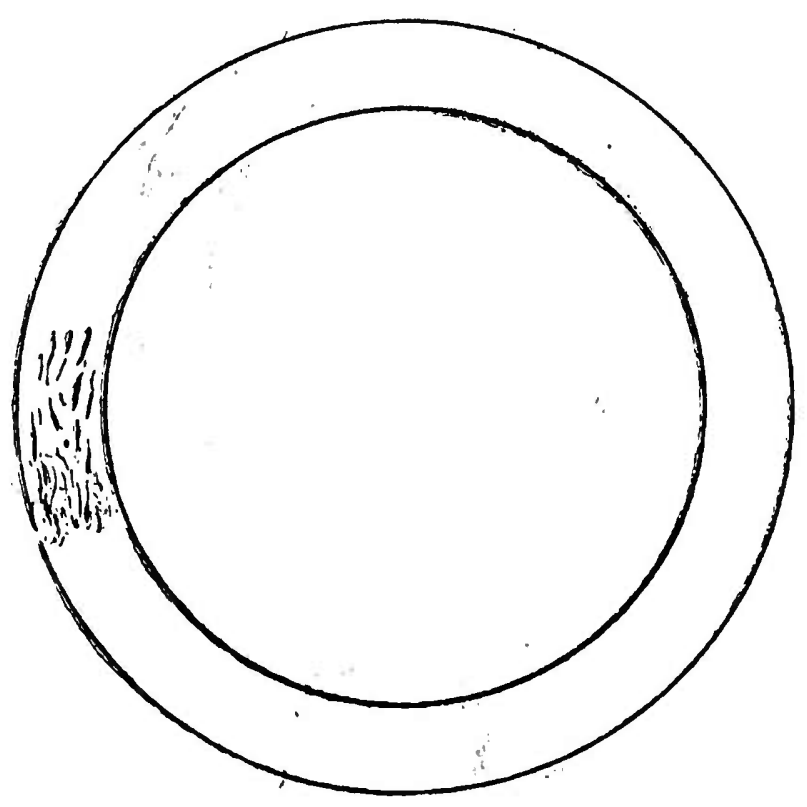

N. 21,b.

culos. Procurando o ventriculo satisfazér ao maximo á todas as excitações, claro está que elle forçosamente se cansará, sobrevindo então o desfallecimento cardiaco e mesmo a morte. Essas nefastas consequencias são mais evidentes na "FLUTTER" onde o rythmo é mais frequente, chegando o ventriculo a apresentar rythmos de 180, 200 e mesmo mais. Contra essa anormalidade somos dotados de dois heroicos medicamentos podendo mesmo um delles ser considerado especifico. Dahi a importancia do estudo que acabamos de fazer e de seu trataménto que vamos agora iniciar. 
REVISTA DE MEDICINA

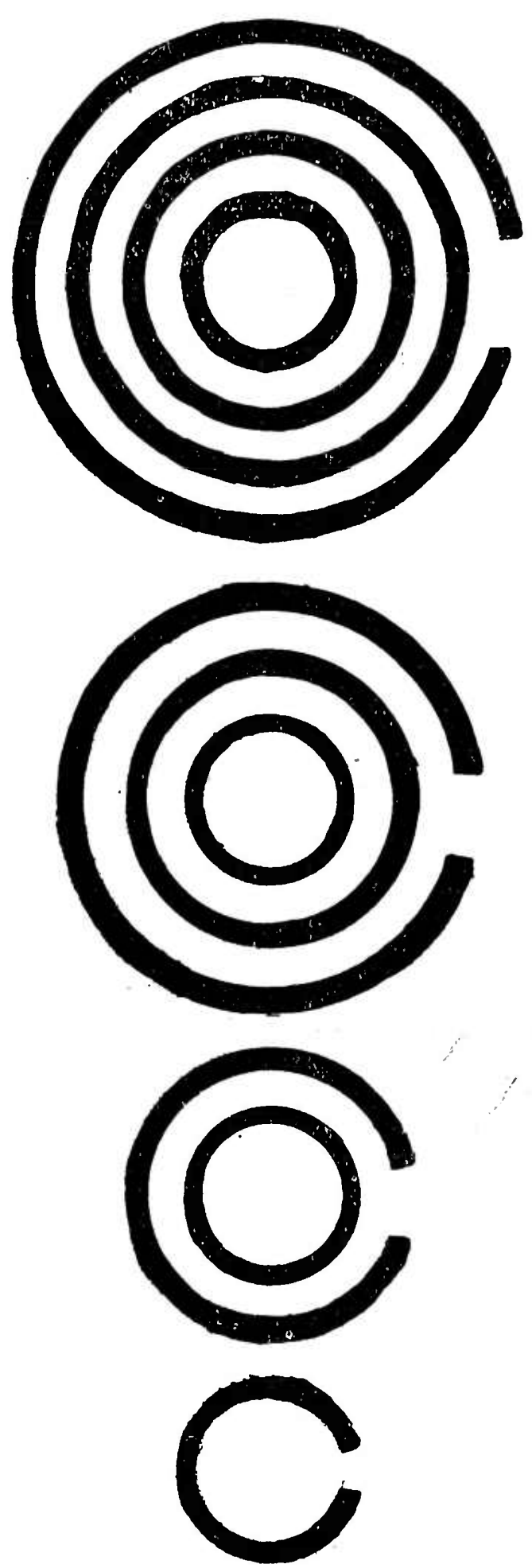

N. 22

Os dois medicamentos usados são: quinidina e digitalis, cujas acções são differentes pelo que vamos estudal-os isoladamente.

Quinidina - A quinidina é um isomero optico da quinina. Dupla é sua acção. Por sua acção directa sobre a fibra, ella augmenta o pe- 
riodo refractario; por sua acção indirecta sobre o vago, elle diminue a velocidade de condução do estimulo. Portanto, tem acçães antagonicas. Pela primeira, augmentando o periodo refractario, ella tende a diminuir - "Gap" difficultando o rythmo circular; pela segunda ella tende a au-
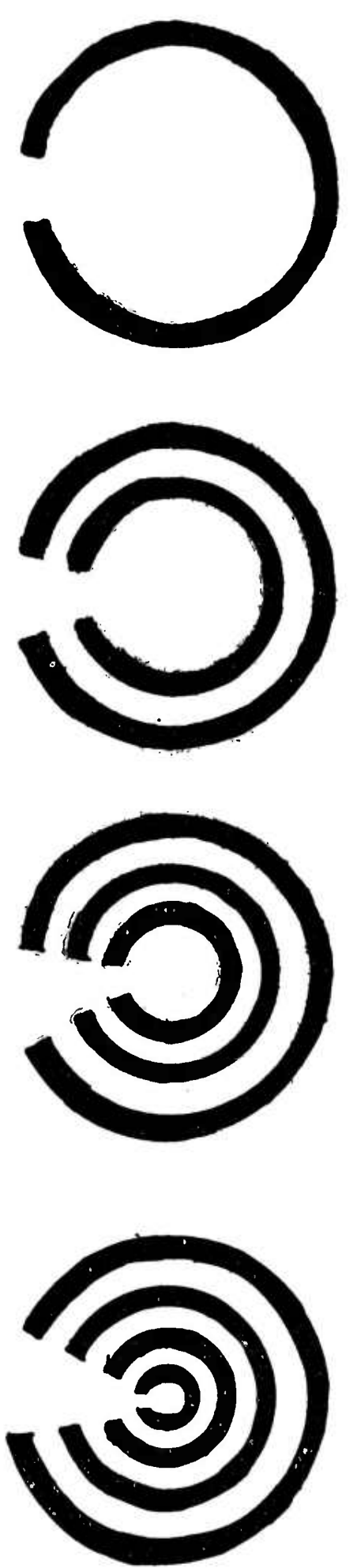

N. 23 
gmentar o "Gap" facilitando portanto o rythmo circular. No conflicto desduas acçães antagonicas prevalece a primeira - augmento do periodo refractario. - Assim, dando quinidina a um individuo ou a um animal que se apresenta com "FLUTTER" ou com "FIBRILAÇÃO AURICULAR, teremos em consequencia o que nos mostra o eschem?.$^{\circ} 22$. Aur gmentando o periodo refractario ella teriderá a fazer desapparecer o "Gap" Uma vez̧ desapparecido o "Gap" em um dado annel, a cmda procura um outro mais externo onde possa ainda circular e assim progressivamente até não haver mais musculo para a onda de excitação circular., Cessado o movimento c.rcular, está desapparecido o ponto anormal de excitação, passando novamente o rythmo a ser regido pelo N. S. A. Isso que acabamos de dizer pode ser consrolado experimentalmente por sas duas acções antagonicas prevalece a primeira-augmento do periodo

Digitalis: - Tambem aqui temos uma dupla lacção. Por sua acção directa a digitalis tende a augmentar o periodo refractario e a diminuir a velocidiade de condurção. Por sua acção indirecta ella estimula o vago trazendo uma diminuição do periodo refractario. Ha nesse caso predominancia da ultima, pois que essa tem a ajudal-a a diminuição da velocidade de conducção. Por sua acção indirecta ella estimula o vago trazendo uma diminuição do periodo refractario. Ha nesse caso predominancia da ultima, pois que essa tem a ajudal-a a diminuição da velocidade de conducção, devido a acção directa; factores esses que trazem um augmento do "Gap" Assim fazenido-a agir sobre a "FLUTTER" ou sobre a FIBRILAÇúO AURICULAR, teremos o que mos mostra o eschema n. ${ }^{\circ}$ 23. Havendo diminuição do "Grap" a onda poderá circular em um annel mais interno e assim progressivamente. Além dessa acção devemos considerar á acção especifića da digitalis sobre as fibras differenciadas do fe:xe "de Hiss, trazendo uma diminuição da condução, tendendo, mesmo a abolil-a, trazendo bloqueio auriculo ventricular.

Conhecidas as acções desses dois medicamentos vejamos como na pratica devemós proceder. Se a um caso de "FLUTTER" ou de FIBRILAÇÃO com uma frequencia de 300 ondas por minuto na auricula, e apresentando o ventriculo, pela impossibilidade de responder a todas as excitações, um rythmo a $2: 1$, ou sejam 150 contracções por minuto, applicarmos quinidina, quando a frequencia chegar a 200 ondas por minuto, o ventriculo passará a responder a todas ellas, portanto a bater 200 
vezes por minuto em lugar de 150 . Ha nesse caso peiora consideravel para o paciente. Se dermos digitalis, teremos um augmento na fréquencia das ondas na auricula, passarido por ex. a 500. Nesse cáso o rythmo não será ma:s a $2: 1$ passando a ser a $3: 1$ ou mesmo $4: 1$, e o ventriculo baterá com uma frequencia de 166 ou de 125 por minuto. Ha nesse caso peiora ou melhora das condições do pacienie. Levando, porem, em consideração a sua acção sobre o feixe de Hiss, teremos sempre melhora das condições do ventriculo, embora haja peiora nas condições da auricula.

Feitas essas considerações qual o criter o que devemos ter na pratica? Em primeiro lugar devemos dar digitalis em doce alta afim de diminuir a conducção no feixe de Hiss e desse modo livrar o ventriculo da influencia nefasta da auricula. Em segundo lugar, se nos acharmos em presença de "FLUTTER" devemos dar quinidina afim de restabelecer o rythmo nodal. Se, ao contrario, nos acharmos em presença de FIBRILAÇÃO AURICULAR e se essa já datar de muito tempo, devemos nos abster de dar quimidina.

Porque assim procedemos? Quando a FIBRILAÇÃO AURICULAR data de longo tempo, ha sempre na auricula graride quantidade de coagulos que, pelo restabelecimento do rythmo nodal, forçosamente seriam lançados na circulação geral, podendo acarretar morte subita por embolia. Qual o criterio para sabermos do resuitado do tratamento? $\mathrm{Pa}$ ra quinidina, cuja acção se desanvolve principalmente sobre o movimento circular, o unico criterio que temos é o controle pelo electrocardiogramma, pelo que não a devemos empregar sem o auxilio desse methodo de exame. Para digitalis, que póde provocar um movimento circular e originar a FIBRILiAÇÃO AURICULAR quando dada em dose excessiva, se nos falta o electrocardiographo para controle, poderemos em parte compencal-o pela ccriagem do pulso e pelo conhecimento do deficit cardiaco (differença entre o numero de batimentos do coração e o numero de pulsações em um dado per:odo de tempo).

iDesse modo temos termirada a nossa palestra. Procuramos, na medida de nossas forças, tornar claras essas idéas e desse modo tornar util o tempo que vos roubamos.

\section{Dr. Jairo Ramos}

(*) Todos os eschemas que illustram este trabalho foram tirados dỏ já citado livro de Th. Rewis, com excepçāo dos de ns. 22 e 23. 